\title{
MyTribe: Postsubcultural manifestations of belonging on social network sites
}

Brady Robards and Andy Bennett (Griffith University)

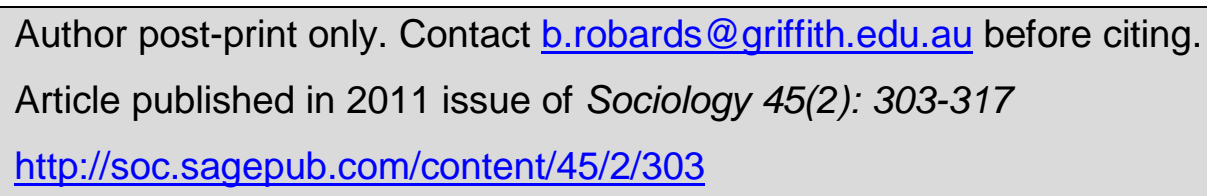

\begin{abstract}
Since the early 2000s, sociologists of youth have been engaged in a debate concerning the relevance of 'subculture' as a theoretical framework in the light of more recent post-modern influenced interpretations of youth identities as fluid, dynamic and reflexively constructed. Utilising ethnographic data collected on the Gold Coast in Queensland, Australia, this article considers such debates in relation to social network sites such as MySpace and Facebook. Although on-line identity expression has been interpreted as exhibiting subcultural qualities, preliminary empirical research informing this article lends itself to a more neo-tribal reading.
\end{abstract}

Keywords: identity; neo-tribe; networking; social network site; subculture; youth.

This paper investigates the postsubcultural turn in youth cultural studies with reference to on-line social network sites. Although there is a growing body of literature examining the social significance of social network sites for youth, little attempt has been made in this literature to map the patterns of on-line engagement and interaction between young people with reference to the ongoing subculture / postsubculture debate in other areas of youth cultural studies. A central contention of the paper is that although such forms of engagement and interaction ostensibly exhibit subcultural characteristics, when subject to empirical scrutiny a more postsubcultural quality becomes evident in young people's everyday use and perception of social network sites. The paper is divided into four main parts. In the first part we explore the subculture / postsubculture debate in more depth and also consider extant work on young people's everyday use of information communication technologies. In the second part of the paper we outline the methodological approach underpinning the empirical research that informs our findings. The third part of the paper presents an in-depth discussion of our findings; through close analysis of interviewee responses, we endeavour to illustrate the extent to which the virtual spaces of communication offered by social network sites appear to accentuate existing trends towards 
reflexively derived, identity projects as identified by post-subcultural theorists in earlier work. In the final part of the paper, we suggest that although our findings tend to support existing postsubcultural explanations of youth culture, particularly those inspired by neotribe theory, at the same time they offer new ways of understanding the nature and significance of such post-subcultural forms of association among young people.

\section{Subculture to postsubculture}

The concept of subculture acquired ready usage in research on patterns of youth leisure and style through the work of the Birmingham Centre for the Study of Contemporary Culture (see Hall and Jefferson, 1976). Borrowing 'subculture' from the Chicago School, where it had been used to construct a sociological explanation of youth deviance (see, for example, Merton, 1957; Becker, 1963), the CCCS adapted the concept as a means of providing an interpretation of the stylistic responses of young working class males in post-Second World War Britain. According to the CCCS, post-War British youth subcultures, by dent of their quasi-gang structure, were illustrative of continuing expressions of class-based solidarity among working class youth. The CCCS work provided theoretical tools for moving beyond the pessimistic reading of mass popular culture offered by Frankfurt School writers, such as Adorno and Horkheimer (1969), and mass cultural theorists, notably MacDonald (1953). The CCCS regarded working class consumers not as passive recipients of mass cultural products, but rather saw such products as a lever for forms of hegemonic struggle. Subsequent CCCS work on youth by Hebdige (1979) provided a more elaborate interpretation of working class youth's use of style and other resources in what he referred to as semiotic guerrilla warfare. Using Levis Strauss's (1966) concept of bricolage and Barthes' (1977) concept of signifying practice, Hebdige considered how the visually spectacular image of punk rock in late 1970s Britain resonated with the socio-economic climate of an industrial nation in decline.

The dominance of subcultural theory held sway in youth cultural studies until the late 1990s when a new series of critical debates emerged concerning the continuing validity of the concept subculture vis a vis an alternative theoretical paradigm referred to as 'postsubculture'. Originally coined by Redhead (1990), the term post-subculture was substantially developed, and theorised, by Muggleton (2000) in work suggesting that contemporary youth culture can no longer be regarded as a direct reflection of class background; rather argues Muggleton, youth identities today are a product of individual 
choice and reflect the heightened reflexivity that is part and parcel of late modern, consumer-based societies (see also Miles, 2000; Chaney, 2004).

Similarly, in work focusing on youth and music, Bennett $(1999,2000)$ argues that the collective expressions of contemporary youth, rather than adhering to the fixity of class and neighbourhood based subcultures as depicted, for example, in the work of Brake (1985), exhibit qualities more closely associated with what French sociologist Maffesoli terms neotribes. According to Maffesoli neo-tribes are 'without the rigidity of the forms of organisation with which we are familiar, [tribe] refers more to a certain ambience, a state of mind, and is preferably to be expressed through lifestyles that favour appearance and form' (1996: 98). The deployment of neo-tribe theory in youth cultural research has been such that it has become a significant element in the post-subcultural turn (see, for example, St. John, 2003; Luckman, 2003; Cummings, 2006).

The subculture / postsubculture debate has continued, giving rise to a series of critical positions on the continuing currency - or not - of subculture as a meaningful concept for understanding the leisure practices of contemporary youth. Hodkinson (2004) has argued that while postsubultural theory may be of relevance for some aspects of contemporary youth cultural practice, for example in relation to dance culture, other youth cultural groupings such as 'goth' exhibit qualities of collective and stylistic fixity that adhere more closely to conventional subcultural readings. In a similar fashion, Shildrick and MacDonald (2006) suggest that class-based inequality continues to play a critical role in many neighbourhoods and regions, impacting on access to leisure resources and strongly informing young people's sense of themselves and their peer group allegiances. Finally, Roberts et al. (2009) contend that geographic location can also play a crucial part in determining young people's aesthetic attachment to and understanding of leisure resources. One notable facet of this, argue Roberts et al. is that those young people living in regions outside the central power bases for leisure capitalism, such as Eastern Europe and parts of the Russian Federation, often tend to exhibit far more conservative and stable tastes in music, fashion and associated leisure practices.

Significantly, despite the high level of debate concerning this topic, little attention has been paid to its significance for our understanding of young people's use of the internet and social media. As a social phenomenon, the internet has had a powerful and lasting impact on the configuration and operation of Western (and, increasingly, non-Western) society. Bowker (2007: 21) contends that the widespread adoption of the internet has been as critical as the advent of the printing press and the development of written records, although 
its potential, in many ways, even exceeds these paradigmatic shifts. The notion of the 'global village', first imagined by McLuhan (1962) in the 60s and fully realised in the early 90 s with the widespread adoption of the internet, still persists as a powerful metaphor. However, as the internet is increasingly embedded into everyday life - the site upon which the 'interplay' between culture and structure takes place (Bennett 2005: 1) - the global village loses its utopic optimism and its ethereal quality. Instead, the politics of the everyday, bound by issues of taste and belonging which are central to the post-subcultural debate, become the key concern for the average internet user. While popular discourse around these issues continues to build, sociological work in this area is still required, if it can be enabled by a renewed sense of focus on the everyday lives of internet users.

There are, however, notable exceptions to this gap in the literature such as Hodkinson's $(2002,2003)$ work on online goth subculture where the post-subcultural debate meets some resistance. Hodkinson argues that while the internet can potentially 'enhance cultural fluidity' (2003: 285) - enabling a post-subcultural reading of the space - it 'can also function to enhance and intensify the boundaries that separate cultural groupings' (2003: 285). Thus, Hodkinson identifies the internet as a medium that can on the one hand reinforce and perpetuate traditional subcultural models of belonging, while on the other also providing a platform for multiple intersections of varying styles, tastes, lifestyles and cultural practices, generating a sense of belonging more consistent with a neo-tribal model. Hodkinson stresses the former through his fieldwork with goths, arguing that just as in offline social situations, individuals online tend to gravitate towards those with whom they share some sense of familiarity. However, Hodkinson's later empirical work with Lincoln (2008) which likens the use of online journals by teenagers to the importance of bedrooms as spaces for the articulation of identity, seems to soften on this point somewhat, arguing that 'rather than forming fixed collective groupings... young people today are more likely to... [negotiate] personal paths through a myriad of temporary and partial identities' (Hodkinson and Lincoln 2008: 29). It is not our contention here to argue against the reality that individuals seek familiarity in social encounters as argued by Hodkinson. Rather, we intend to provide an additional dimension to this argument by considering and applying a new configuration of online sociality that centres on the individual as the pivotal node in a network of contacts rather than on a shared sense of style as exemplified by Hodkinson's work on goths. We will discuss this new conceptualisation of online sociality and belonging through the work of Joinson (2008), Jones et al. (2008) and boyd (2007a, 2007b) in the following section. 
Kahn and Kellner (2003) offer yet another conceptualisation of subculture on the internet by examining the politicised nature of these groups. Consistent with Turkle's (1995) reading, Kahn and Kellner argue that identities on the internet are 'often hybridic and complex' with 'post-subcultures' regarded as 'dissolving classical cultural and political boundaries that appear too rigid and ideological for Internet life' (2003: 300). However, they go on to identify what they term online post-subcultures as also exhibiting 'clearly defined political orientations' (ibid) which again reproduces a tension between the unitary and multiplicitous configurations of self and belonging appearing in the literature.

Other cultural research on the internet as a whole has often tended to take 'subculture' as something of a given. Healy, for example, describes the internet 'as a loose collection or "ecosystem" of subcultures', while Bassett refers to internet chat rooms as 'subcultural spaces' (1997: 65; 1997: 538). Similarly, Papacharissi conflates the term subculture with the notion of "subnetworks... of taste or online "caste" systems that reinforce or question existing inequalities' (2009: 205). Problematically, however, such applications of subculture appear to strip the term of its original theoretical context and redeploy it in increasingly arbitrary and unqualified ways (Bennett, 2004). Moreover, such work often makes assumptions about the relevance of subculture without recourse to empirical data. As such, it is very difficult to gain a sense of the social composition of such internet 'subcultures' and the common points of convergence - or not - between members. To this, of course, must be added the increasing distinction between what could be referred to as 'emic' and 'etic' notions of subculture. Thus, once an exclusively theoretical terminology, through its incorporation and use in and by the contemporary media and leisure industries, subculture has increasingly entered the realm of vernacular discourse. As Bennett (2004) has argued, such vernacularisation of subculture has coincided with the emergence of the internet as a new tool of communication - and cultural identification - between young people. As such, the internet may well give rise to new, reflexively constructed notions of subculture through which young people include and exclude themselves from particular forms of cultural association. Subculture may also be used as a discursive tool through which young people understand themselves as crossing over a series of different lifestyle practices and sensibilities. Indeed, as this article seeks to illustrate, when subject to empirical scrutiny young people's use of the internet exhibits tendencies that align far more readily with postsubcultural / neo-tribal types of association than with subcultural models of explanation. Using empirical data generated by one of the authors, the article develops this argument 
with reference to specific examples of social network sites by young people in the Gold Coast region of Australia.

\section{Background and methodology}

In 2003, the social network site Friendster entered into popular usage in the U.S., effectively becoming the first widely adopted social network sites (boyd 2007b: 133). In the same year, MySpace was launched, eventually overtaking Friendster in popularity by 2006, only to be overshadowed by Facebook in 2008. Key characteristics that each of these sites share include profile pictures, auto-biographical 'about me' sections and Friends lists, the latter constituting the networked configuration of these sites. While different sites often include varying features (blogs, for instance, have operated slightly differently on each site, as has the 'status update' and the 'wall/comment' field) they are all, essentially, a collection of user-created profiles which are linked together. These sites have become a key medium of not only communication but also social interaction between young people. In early 2010 , the site had 500 million active users worldwide, 8 million of which were located in Australia (Facebook.com, 2010). According to Hitwise Australia, in August 2008, Facebook and MySpace were the fourth and seventh most popular online destinations in Australia respectively, attracting 4.2\% of all Australian internet traffic. A year later, in October 2009, this reach extended to $7.07 \%$ of traffic with MySpace falling to twelfth most popular online destination in Australia and Facebook rising to second place (Hitwise 2008, 2009).

Qualitative research on how young people are using these sites and for what purposes has revealed an interesting trend. Rather than being used to meet new people, social network sites are instead being used to articulate existing and often offline networks of friends, family, colleagues and more casual acquaintances. While these sites still provide the opportunity for networking in the more traditional sense of creating and fostering new social relationships, boyd and Ellison have found that it is not the primary practice on many of them' (2007: 2). Similarly, Joinson's (2008: 1029) quantitative research found that amongst Facebook users, the primary use of the site was to 'keep in touch' with existing friends. Articulating these networks of 'real' people with whom they share some offline or tangible relationship becomes the central practice for many users of social network sites. From an administrative perspective Facebook itself identifies its site not as a networking tool but as a social utility for friends. Facebook policy actively discourages users from engaging with mainly 'internet-only' contacts on their site ('Lauren' in Arrington 2008). Further, Jones et al. found that contrary to reports of MySpace users often having large 
outrageous lists of 'Friends' that would be unlikely to represent an offline network of contacts, the average user's network contained 145 Friends with 58\% having less than 100 (2008: 2). These findings imply a relatively fixed clustering of relationships and contacts, reminiscent of face-to-face networks.

In applying Goffman's theatrical metaphor of identity performance to social network sites, Pearson (2009) examines how users construct themselves online, enacting a concept of self to an imagined yet sometimes unknown audience.

These performances exist within the imagination of users who then use tools and technologies to project, renegotiate and continuously revise their consensual social hallucination... to create not only online selves, but also to create the staging and setting in which these selves exist (Pearson, 2009, n.p.).

While Pearson's research does not address the complexity of privacy controls across social network sites or the awareness of many users when it comes to controlling who can and cannot view their profiles, she does - importantly - draw attention to how online forms of sociality tend to collapse the front-stage / back-stage modes of performance in Goffman's theoretical framework. Appropriate identity performance can become problematic when the potential audience can consist of contacts from multiple social environments: friends, parents, co-workers, distant relatives, students, mentors, etc. Creating an authentic and properly coded 'image' online is a complex and heavily loaded process (Peeters, 2008: 7). However, as this article begins to demonstrate, what may have been a serious hurdle of identity performance previously is simply another component of online sociality that young people are negotiating with and incorporating into their everyday lives.

Performing identity online is essential to facilitate social interaction, allowing users to, in Bauman's terms, 'go on in each others' presence' (1996: 19). boyd argues that 'social network sites allow publics to gather' (2007a: 8) in a similar fashion, she argues, to how a shopping centre allows people to gather and socialise publically. When asked about the underlying motivation for participation and the actual activities that constitute participation in social network sites, boyd's young respondents provided somewhat vague yet revealing answers such as 'I don't know... I just hang out,' and 'cuz that's where my friends are' (Participants in boyd 2007a: 9). 'Hanging-out' has been identified as an important component in the social lives of young people, often simply taking the form of meeting other young people without adult supervision at home or in a public space such as a 'mall or a 
park' (Garner 2002: vii). Conceptualising social network sites in this way enables traditional questions in youth studies around identity and subcultural notions of belonging to be framed in a contemporary context and applied to a relatively new medium of youth sociality. To return to our earlier observation, rather than being concerned with fundamentally new modes of sociality, the young people that are engaging with these sites on an everyday basis are doing so in a highly fluid manner, incorporating these technologies into their everyday practices. It is not these sites that are shaping the lives of their users, but rather quite the opposite. Thus, sites like MySpace and Facebook do not reconfigure social relationships or systems of identity and belonging, but they do make these dimensions of everyday life highly visible, exposing existing social practices.

Preliminary data from a qualitative study being conducted on the Gold Coast has revealed support for the arguments outlined here, in addition to contributing a new perspective to the post-subcultural debate. The study involved in-depth semi-structured interviews with 32 young people (11 males, 21 females) aged 18 to 27, coupled with observation and discourse analysis of the participants social network site profiles. The interviews sought to make inquiries into the online social practices of young people, uncovering how their identities are constructed and subsequently situated within, across or in-between systems of belonging and whether those systems can be conceptualised as subcultures or something closer to a neo-tribal configuration of belonging. Themes include the range and extent of participants networks, their strategies for dealing with unsolicited contact and their negotiations with potentially awkward social situations such as romantic break-ups, the rejection of Friend requests, how to negotiate the division between private and public spheres of life and dealing with inappropriate content. Findings related to determining Friendship and dealing with unsolicited contact have been discussed elsewhere (Robards 2010).

Initial participants were recruited from undergraduate humanities courses at Griffith University on the Gold Coast, and subsequent interviewees were recruited through a process of selective snowballing to broaden the participant pool. While snowballing can potentially narrow a participant pool rather than diversifying it, in this instance a relatively selective approach was taken. Specifically, when inviting interviewees from the undergraduate population to suggest other potential participants, only contacts without a University background were pursued. However, despite this approach, only five participants did not have University backgrounds. While this would appear to be a strong limitation of 
the research, we would contend that a University background does not immediately correlate with notions of privilege and class, especially on the Gold Coast.

The Gold Coast, both a region and a city in South East Queensland on the mid-east coast of Australia, is perhaps best known as a tourism destination coupled with a recent and strong surge of local development - in the order of a 3.5 percent increase in population each year since the early 1990s (KPMG and University of Queensland in Wise, 2006: 177). As a relatively new yet quickly developing city with a largely transient population oriented towards construction and service industries, the Gold Coast is itself an interesting context for discussions of privilege, class, neighbourhood, community, belonging, identity and traditional correlations between social, cultural and economic capital. Within the context of this research, these issues become increasingly difficult to pin-down and work into a methodological approach. However, due ethical concern has been given to providing a relatively representative sample of young people from the Gold Coast from a variety of backgrounds and situations. The anonymity of these individuals has been preserved throughout the research, and in this article interviewees have been assigned alias' to maintain the de-identification process.

\section{Youth engagement with social network sites on the Gold Coast}

Fundamental to the performance of identity (regardless of whether or not this performance is conceptualised as online and thus often lesser in the real/virtual dichotomy) is the notion of belonging, which in youth studies and broader sociological terminology is often analysed through subcultural frameworks. As Bauman observes, identity as a concept was 'born out of the crisis of belonging' (2004: 20) and yet simultaneously, identity is often expressed in terms of belonging. However, as indicated earlier, this study has begun to reveal that the ways in which young people describe their own sense of belonging is increasingly fluid and broad. Rather than adhering to the strict boundaries of belonging implied by subcultural frameworks, the identities being performed on social network sites (and subsequently reflected upon by participants) would align more closely (although not absolutely) with a neo-tribal reading of belonging. In essence, although invoking subcultural terminologies as a means of delineating terms of cultural association with others, the everyday language and terms of reference used by the young people in this study point to a series of lifestyle projects which are highly reflexive, individually derived and acted out across a diverse range of sites and spaces both in the physical and virtual realm. In this sense, the findings of this study tend to bear out Bennett's (2004) earlier observation that, rather than offering a 
new domain for the construction of 'subcultural' relationships, internet communication between young people often tends to replicate what is already apparent in face-to-face relationships. In the case of the present study, neo-tribal tendencies already in evidence at the face-to-face level, are often accentuated and given a greater degree of presence through participation in social network sites.

All interviewees have thus far confirmed boyd and Ellison's (2007) observation that social network sites such as MySpace and Facebook are used primarily as social utilities to connect existing contacts rather than to generate new ones. However, several interviewees have indicated that social network sites can also be used as a 'next-step' information gathering exercise after an initial offline meeting. '....if you meet someone at a party they'll add you then you might go on a date or something... but if you just saw them at a party, you might not take it further' (Alison, 19). However, when another interviewee was asked to explain why she didn't keep information (such as hobbies and interests) on her profile upto-date, she explained '... it's not important to me... meet me and ask me, don't see that I'm a person on Facebook' (Melissa, 20). The same interviewee went on to extol the virtues of social network sites, but emphasised their role as facilitators for offline sociality.

When initially given the opportunity to comment on specific instances and practices of identity performance on site profiles, most interviewees were fairly evasive and vague. Despite the open process of identity performance, the actual reflexive description was unsurprisingly more difficult to tease out. To overcome this difficulty, interviewees were asked to describe what kind of story (or movie, as this often provided a more immediate response) might be written about them if the only information available to the imagined author was their profiles. 'It'd be about urban exploration in an abandoned warehouse which ends up becoming my home which is made into a loft which I hold raves at' (Shannon, 23). Not all responses were so specific: ' ... a young woman moving away from home, going to a new country, travelling around, having lots of friends... just all the usual stuff nineteen year-olds do' (Naomi, 19). While each response was different and articulated in varying ways, the crucial point here is that each interviewee was able to draw out a relatively cohesive narrative from the information presented on their profiles, such as images, hobbies, status updates and other interests. The early critics of virtual identity (See Turkle, 1995 for a discussion on identity crisis) argued that the 'reflexive questioning, irony and... playful probing' inherent in online identity construction would result in a situation where 'the centre fails to hold' (Gergen in Turkle, 1995: 257), with the individual becoming saturated in multiplicity to the point of incoherence - a sentiment which persists in some 
media reports and popular discourse surrounding the internet today. Contrary to this discursive trend, the research reported here indicates the opposite. When asked to think reflexively about what constitutes their identity in order to demonstrate some version of that self on a social network site, interviewees demonstrated relatively structured concepts of self-identity. While these identities can often be multiple, fluid and eclectic, they are also simultaneously coherent in these cases.

The profiles that constitute social network sites rely on what are generally regarded as subcultural frames of reference to act as referents in the process of performance: images (or other invocations) of bands, a list of favourite books or a profile picture featuring the pages author in her favourite football jersey (ii). While these performances require some level of what Thornton refers to as 'subcultural capital' (1996) to both enact and decode, the overall identity these performances contribute to does not adhere to the rigidity implied by subcultural categorisation.

Grant, for example, is a 20-year-old male living on the Gold Coast in his fourth year of an Engineering degree, saw his MySpace profile as 'a picture of what your personality is like, and what you like' (Grant, 20). He saw dance music as an important part of his profile and he recognised that it situated him as someone who attended nightclubs that played dance music. However, he also made a point of separating himself from the practices of illicit drug usage and smoking which he saw as inherently involved with his taste in music and the practice of going to night clubs. David, an 18-year-old male living on the Gold Coast and working in the hospitality and retail industries made similar connections with his interest in dance music and the practice of attending night clubs. However, he went further to implicate his taste in music in his self-narrative: 'that music is my life' (David, 18). David also foregrounded his sexuality as central to his identity, seeing himself as 'a typical gay 18 year old having fun on the Coast' (David, 18).

By deploying dance music as an undercurrent element in their online identity performances, both Grant and David reflexively observed that their taste in music implied a subcultural connection to other practices - namely going to night clubs (for both) drug usage (for Grant) and the gay community (for David). These interviewees recognised the implicit rigidity of conceptualising themselves in subcultural terms and subsequently mounted what we might effectively call a postsubcultural critique of their own online identity performances. By rejecting some associated practices (drug usage) and strengthening other, possibly tenuous associations (gay community) the interviewees were recognising the expected or implied rigidity in their common practice and effectively resisting that 
rigidity. This observation also points to an often overlooked aspect of Muggleton's (2000) reading of postsubcultural identity. According to Muggleton, although postsubcultural identities are most readily identified through the visual pick-and-mix assortment of styles adopted by post-subculturalists, equally important are the identity discourses that young people create to explain such eclecticism. Such discourses also draw on elements of perceived 'subcultural' narratives - in the above case, club culture, drug use, and gay identity - selectively adopting particular aspects of these narratives and leaving out other aspects to produce an individualised narrative of identity. However, the everyday operationalisation of such narratives, across an array of cultural practices is, by contrast, suggestive of an inherently post-subcultural, neo-tribal form of engagement with different clusters of youth cultural practice as these unfold across the Gold Coast region.

When asked to describe what subculture is, all interviewees defined the concept simply as a small group within a parent culture and gave examples such as 'hardcore kids', 'skaters', 'footie boys' (Tim, 18) and the more traditional 'punks' right through to more abstract, non-traditional categorisations such as 'gym-junkies'(ii) and the 'club subculture' (Eric, 20). Each description of a proposed subculture included some preconceived notions about clothing, musical interests, attitudes (usually towards alcohol and drugs) and even which groups the interviewee might get along with the most. However, these descriptions were almost always reflexively positioned as awkward, ill-fitting generalisations. For example, no interviewees identified themselves as strictly belonging to a single subculture, although they did state that they recognised elements of subculture within their own selfnarratives. However, there was a clear sense that these articulations of belonging were positioned in-between what they described as subcultures or rather what they conceptualised as models of belonging, thus resisting alignment with pre-existing groups of individuals. Tim (18) for instance described himself as 'a drifter' between his friendship groups that he characterised according to cultural and sporting practices. Eric (20) was more articulate: '... while I may belong to that [subculture], I wouldn't say I only belong to that. I think I'm part of other ones as well. And I wouldn't say I'm totally involved in them'.

These kinds of reflexively constructed accounts of identity are consistent with Muggleton's notion of liminal subcultures in which 'groups have begun to break out of the very boundaries through which they are defined' (2000: 75). Social network sites require individuals to piece together what they constitute as self-identity, and it is to be expected that this reflexive process will intensify the need for young people to develop a coherent sense of self (or not, by way of resistance) in order to participate in digital culture. While 
Muggleton examines eclecticism in terms of fashion and appearance, we would assert that the rigidity and implied cohesiveness of the subcultural model is problematised by a broader kind of eclecticism, manifest in all cultural configurations: not only fashion but also food, music, sports, travel, films, literature and so on encompassing any form of cultural practice. Whereas Muggleton argues for the category of 'crossover counterculture' or liminal subculture reminiscent of Gottschalks' 'freak style' that is 'unwilling to embrace any recognisable (sub)cultural style,' (Gottschalk in Muggleton 2000: 77) we would extend this subcultural resistance, having observed it in the data from this study, and align it with a neo-tribal reading of belonging. Rather than organising their system(s) of belonging around a particular taste or style (exemplified by the goths in Hodkinson's work) the participants in this study from a general sample of young people on the Gold Coast, Australia, appear to conceptualise their own sense of belonging in a much more multiplicitous (yet, interestingly, simultaneously persistent), inter-connected, fluid and individual-centred way. It is this sense of belonging that we align loosely with Maffesoli's concept of the neo-tribe.

This partial sense of belonging, or belonging to multiple categories is a clear demonstration of a post-subcultural trend emerging in the reflexive construction of identity amongst young people. Rather than belonging exclusively to a subsection of a parent culture and being aware of how (and why) that respective group deviates from general culture, subculture has become a discursive construct, more akin to a palette of tastes that the individual can draw from, modify and remix in achieving a reflexive understanding of self. In this sense, what our study ultimately reveals are a series of etic constructions of 'subculture' operationalised by young people on the Gold Coast to describe a diverse series of lifestyle practices and tastes that are, conceptually speaking, far more closely aligned with current sociological interpretations and applications of neo-tribalism than with subcultural theory. However, while we would argue that the neo-tribe model proposed by Maffesoli (1996) and advanced by Bennett $(1999,2000)$ offers a more conceptually congruent alternative to the subcultural framework, there are instances in which this model, as it stands, is also insufficient to describe the sociality occurring on social network sites.

\section{Re-thinking neo-tribes}

Throughout this article, it has been suggested that the practices of young people on social network sites adhere more closely to the practices and conventions associated with postsubcultural forms of identification than with traditional subcultural models. That said, we also wish to argue that the distinctive ways in which the internet is used by young people, 
and the distinction made here between 'networking' (forming new social relationships) and 'networks' (typified by MySpace and Facebook as sites for the articulation and facilitation of existing social relationships) suggests a need for some refinement of Maffesoli's original neo-tribe model. The practice of online networking (in the more traditional sense) adheres quite neatly with Maffesoli's original deployment of neo-tribe as bespeaking an inherently fragile, ephemeral and essentially fluid form of social engagement. However, the formation of more stable networks (and the articulation of these offline networks in an online space) suggests an emergence of more permanent groupings, albeit ones that are facilitated and managed by a technological medium that transcends conventional understandings of collective social activity. Many participants, for instance, report 'de-briefing' on Facebook after a weekend of partying and socialising, by recounting stories and commenting on images from the weekend's events. It is our contention that a new process of tribalisation is occurring here - one not envisaged by Maffesoli. On the basis of our findings, there would appear to be a critical problem with Maffesoli's theorisation of neo-tribe, notably in its unerring conviction that neo-tribal associations result only in temporal bondings characterised by short-lived bursts of sociality. Nowhere in Maffesoli's interpretation is there scope for the possibility of self-selecting neo-tribal groupings producing their own sense of permanence based around an affectivity grounded in mutual understandings - aesthetic, political, or otherwise. This, however, is precisely what our findings would tend to suggest. While the sensibilities manifested by our interviewees exhibit neo-tribal qualities, the resulting forms of sociality cannot in every instance be read as a series of fleeting and temporal associations. Arguably then, Maffesoli's concept of neo-tribes and associated interpretation of the neo-tribal condition requires some revision. Thus, rather than being held to describe an entire socio-cultural milieu in a constant state of flux, perhaps neotribalism is best characterised as a process of temporal wandering whereby like-minded individuals eventually find each other. Traversing a highly fragmented late modern social terrain, individuals seek each other out and create more permanent, albeit less rigid, forms of association grounded in a reflexive process of self-selection based around perceived commonality in terms of taste, aesthetics, outlook, and other cultural attributes referred to by Chaney (1996) as lifestyles. Due to the cultural fragmentation associated with late modernity, the everyday terrains that individuals must traverse in their search for likeminded others are increasingly vast and multi-layered. Thus, temporary engagement with a variety of collectivities becomes an increasingly necessary step in seeking out those 
individuals and collective spaces (virtual and physical) with whom and within which once feels 'at home'.

To put this in the context of the current article, while there are social spaces on the internet that align much more readily with the ephemeral and impermanent nature of Maffesoli's original conceptualisation of the neo-tribe, social network sites or rather the social ties articulated on these sites, appear to operate very differently. Our findings (consistent with other research in the field, notably charted by boyd and Ellison's 2007 article) indicate that social network sites are simply articulations of collectivity that appear to be crystalising over time. Although not generally spaces for networking in a traditional sense, they are equally tribal in that they are not necessarily bounded by class, locality and so on. Nevertheless, they embody a greater sense of coherence than forms of engagement based around networking and may, in particular cases, solidify into semi-permanent groupings.

\section{Conclusion}

This article has examined the subculture / postsubculture debate in the context of young people's use of social network sites. The aim of the article - and broader research from which the article is drawn - is to ascertain the extent to which the forms of social connection and expressions of on-line sociality displayed by social network site users conform with the basic characteristics of subculture or whether they tend more towards the qualities associated by Maffesoli with neo-tribes. Our current data suggests that social network site users exhibit patterns of on-line behaviour that adhere more with qualities associated with neo-tribes rather than subcultures. At the same time, however, the variations in fixity of social relationships formed via social network sites suggest the need for a critical revision of Maffesoli's original model of neo-tribes in order to account for the possibility of more concrete and stable relationships, generated on social network sites.

The individual-centred systems of social connectivity occurring on social network sites are just one instance of how young people are required to negotiate an increasingly complex terrain of identity that requires coherent, reflexively constructed performances of self. While the research described here is beginning to grapple with these issues and filter the everyday online social practices of young people into sociological frameworks, the dynamic and fluid nature of this terrain and the manifestations of these issues require ongoing investigation and revision. 


\section{Acknowledgements}

We would like to thank the participants in this research for their valuable time and insights.

\section{Notes}

1 Football jersey as in Australian National Rugby League (NRL).

2 Usually men who spend large amounts of time exercising and weight-lifting at a gymnasium.

\section{References}

Adorno, Theodore and Horkheimer, Max (1969) The Dialectic of Enlightenment. Allen Lane: London.

Arrington, Michael (2008) "Facebook isn't a Social Network. And stop trying to make new friends there." Techcrunch.com, Accessed September 29, 2008. Available at: http://techcrunch.com/2008/09/15/facebook-isnt-a-social-network-and-dont-try-to-makenew-friends-there/

Barthes, Roland (1977) 'The Third Meaning', in S. Heath (ed.) Image, Music, Text. London: Fontana.

Bassett, Caroline (1997) 'Virtually Gendered: Life in an on-line world' in K. Gelder and S. Thornton (eds) The Subcultures Reader. London: Routledge.

Bauman, Zygmunt (2004) Identity. Cambridge: Polity.

Bauman, Zygmunt (1996) 'From Pilgrim to Tourist - or a Short History of Identity' in S. Hall and P. du Gay (eds) Questions of Cultural Identity. London: Sage.

Becker, Howard S. (1963) Outsiders: Studies in the Sociology of Deviance. New York: Free Press.

Bennett, Andy (1999) 'Subcultures or Neo-Tribes?: Rethinking the Relationship Between Youth, Style and Musical Taste', Sociology, 33(3): 599-617.

Bennett, Andy (2000) Popular Music and Youth Culture: Music, Identity and Place. London: Macmillan.

Bennett, Andy (2004) 'Virtual Subculture? Youth, Identity and the Internet', in A. Bennett and K. Kahn-Harris (eds) After Subculture: Critical Studies in Contemporary Youth Culture. Basingstoke: Palgrave.

Bennett, Andy (2005) Culture and Everyday Life. London: SAGE. 
Bowker, Geoffrey C. (2007) "The Past and the Internet" in J. Karaganis (ed.)

Structures of Participation in Digital Culture. Columbia: Columbia University Press. boyd, danah (2007a) 'Why Youth (Heart) Social Network Sites: The Role of Networked

Publics in Teenage Social Life' in D. Buckingham (ed.) MacArthur Foundation Series on Digital Learning.

boyd, danah (2007b) "None of this is Real: Identity and Participation in Friendster" in

J. Karaganis (ed.) Structures of Participation in Digital Culture. Columbia: Columbia University Press.

boyd, danah and Ellison, Nicole (2007) 'Social Network Sites: Definition, History and

Scholarship.' Journal of Computer-Mediated Communication, 13(1).

Brake, Mike (1985) Comparative Youth Culture: The Sociology of Youth Cultures and Youth

Subcultures in America, Britain and Canada. London: Routledge and Kegan Paul.

Cannane, Steve (2008) 'MyFace.' Triple J television program Hack Half Hour, ABC

Broadcasting, aired September 22.

Chaney, David (1996) Lifestyles. London: Routledge.

Chaney, David (2004) 'Fragmented Culture and Subcultures' in A. Bennett and K. Kahn-

Harris (eds) After Subculture: Critical Studies in Contemporary Youth Culture.

Basingstoke: Palgrave.

Cummings, Joanne (2006) 'It's More than a T-Shirt: Neo-tribal Sociality and Linking Images at Australian Indie Music Festivals', Perfect Beat, 8(1): 65-84.

Facebook (2010). 'Facebook press room'.

http://www.facebook.com/press/info.php?statistics, accessed January 23, 2010.

Garner, Ruth (2002) Hanging Out: Community-based after-school programs for children.

Westport: Bergin \& Garvey.

Hall, Stuart and Jefferson, Tony (1976) (eds.) Resistance Through Rituals: Youth

Subcultures in Post-War Britain. London: Hutchinson.

Healy, Dave (1997) 'Cyberspace and Place: The Internet as Middle Landscape on the

Electronic Frontier', in D. Porter (ed.) Internet Culture. London: Routledge.

Hebdige, Dick (1979) Subculture: The Meaning of Style. London: Routledge.

'Hitwise Australia' (2008, 2009) Top Websites and Search Engine Analysis Report, accessed 5 August 2008 and 2 November 2009, http://www.hitwise.com/au/datacentre/main/dashboard-1706.html

Hodkinson, Paul (2002) 'Communicating Goth: On-line media', in K. Gelder (ed.) The Subcultures Reader. London: Routledge. 
Hodkinson, Paul (2003) '"Net.Goth": Internet Communication and (Sub)Cultural Boundaries', in D. Muggleton and R. Weinzierl (eds) The Post-Subcultures Reader. Oxford: Berg.

Hodkinson, Paul (2004) 'The Goth Scene and (Sub)Cultural Substance', in A. Bennett and

K. Kahn-Harris (eds) After Subculture: Critical Studies in Contemporary Youth Culture.

Basingstoke: Palgrave.

Hodkinson, Paul and Lincoln, Sian (2008) 'Online journals as virtual bedrooms? Young people, identity and personal space.' Nordic Journal of Youth Research 16(1): 27-46. Joinson, Adam (2008) 'Looking at', 'Looking up' or 'Keeping up with' People? Motives and

Uses of Facebook.' Computer-Human-Interaction Conference Proceedings: 1027-1036. Jones, Steve, Millermaier, Sarah, Goya-Martinez, Mariana and Schuler, Jessica (2008) 'Whose space is MySpace? A content analysis of MySpace profiles.' First Monday, 13(9).

Kahn, Richard and Kellner, Douglas (2003) 'Internet Subcultures and Oppositional Politics', in D. Muggleton and R. Weinzierl (eds) The Post-Subcultures Reader. Oxford: Berg. Levi-Strauss, Claude (1966) The Savage Mind. London: Weidenfeld and Nicholson. Luckman, Susan, (2003) 'Going Bush and Finding One's "Tribe”: Raving, Doof and the Australian Landscape', Continuum: A Journal of Media and Cultural Studies, 17(3): 31832.

McLuhan, Marshall (1962) The Gutenberg Galaxy: The making of typographic man.

Toronto: University of Toronto Press.

MacDonald, Dwight (1953) 'A Theory of Mass Culture', in B. Rosenberg and D. White (eds) Mass Culture: The Popular Arts in America. Glencoe, Illinois: The Free Press, Maffesoli, Michel (1996) The Time of the Tribes: The Decline of Individualism in Mass Society, trans. D. Smith. London: Sage.

Merton, Robert K. (1957) Social Theory and Social Structure. London: Collier-Macmillan Ltd.

Miles, Steven (2000) Youth lifestyles in a changing world. Buckingham, UK: Open University Press.

Muggleton, David (2000) Inside Subculture: The Postmodern Meaning of Style. Oxford: Berg.

Papacharissi, Zizi (2009) 'The virtual geographies of social networks: a comparative analysis of Facebook, LinkedIn and ASmallWorld', New Media \& Society, 11(2): 199-220. 
Pearson, Erika (2009) 'All the World Wide Web's a stage: The performance of identity in online social networks.' First Monday, (14)3.

Peeters, Heidi (2008) 'The Networked Self: Autofiction on MySpace.' Image \& Narrative, 19: 1-13.

Redhead, Steve (1990) The End-of-the-Century Party: Youth and Pop Towards 2000. Manchester: Manchester University Press.

Robards, Brady (2010) 'Randoms in my bedroom: Negotiating privacy and unsolicited contact on social network sites.' PRism, (7)3

Roberts, K, Pollock, G., Tholen, J. and Tarkhnishvili, L. (2009) 'Youth leisure careers during post-communist transitions in the South Caucasus', Leisure Studies, 28(3): 261 - 77.

Shildrick, T. and MacDonald, R. (2006) 'In Defence of Subculture: Young People, Leisure and Social Divisions', Journal of Youth Studies, 9(2): 125 - 40.

St John, Graham (2003) 'Post-rave technotribalism and the carnival of protest', in D. Muggleton and R. Weinzierl (eds) The Post-subcultures Reader.Oxford: Berg.

Strauss, Levi (1966) The Savage Mind. Chicago: University of Chicago Press.

Thornton, Sarah (1996) Club Cultures: Music, Media and Subcultural Capital. London: Wesleyan University Press.

Turkle, Sherry (1995) Life on the Screen: Identity in the age of the internet. New York: Touchstone.

Wise, Patricia (2006) 'Australia's Gold Coast: A city producing itself' in C. Linder (ed.) Urban Space and Cityscapes: Perspectives from Modern and Contemporary Culture. London: Routledge.

Brady Robards is an Associate Lecturer and PhD Candidate within the School of Humanities at Griffith University on the Gold Coast and an affiliate of the Griffith Centre for Cultural Research. Brady's research explores how young people use online social spaces to construct a reflexive sense of identity. His thesis is concerned with how that sense of self is positioned within, across or in-between systems of belonging and how these systems of belonging (and the way scholars conceptualise them) are changing. Brady is a member of the Australian Sociological Association (TASA), the Cultural Studies Association of Australasia (CSAA) and the Association of Internet Researchers (AolR).

Andy Bennett is Professor of Cultural Sociology and Director of the Griffith Centre for Cultural Research in Queensland, Australia. He has authored and edited numerous books 
including Popular Music and Youth Culture, Cultures of Popular Music, Remembering Woodstock, After Subculture and Music Scenes. He is a Faculty Associate of the Center for Cultural Sociology, Yale University, and an Associate of PopuLUs, the Centre for the Study of the World's Popular Musics at Leeds University. He is also Editor in Chief for the Journal of Sociology.

Date submitted November 2009

Date accepted July 2010 